\title{
Transcriptional analysis of Kluyveromyces marxianus for ethanol production from inulin using consolidated bioprocessing technology
}

Jiaoqi Gao ${ }^{1}$, Wenjie Yuan ${ }^{1 *}$, Yimin Li ${ }^{1}$, Ruijuan Xiang ${ }^{1}$, Shengbo Hou ${ }^{1}$, Shijun Zhong ${ }^{1}$ and Fengwu Bai ${ }^{1,2}$

\begin{abstract}
Background: Ethanol production from non-crop materials, such as Jerusalem artichokes, would make a great contribution to the energy industry. The non-conventional yeast, Kluyveromyces marxianus, is able to carry out ethanol fermentation of sugar molecules obtained from inulin-containing materials by consolidated bioprocessing. Lower inulin concentrations and micro-aeration can lead to a relatively fast and ideal fermentation process; however, it is unclear what causes the inhibition of higher concentrations of inulin and the promotion effect of aeration.

Results: Next-generation sequencing technology was used to study the global transcriptional response of K. marxianus Y179 under three fermentation conditions, including $120 \mathrm{~g} / \mathrm{L}$ inulin without aeration (120-N), $230 \mathrm{~g} / \mathrm{L}$ inulin without aeration (230-N), $230 \mathrm{~g} / \mathrm{L}$ inulin with aeration by ORP controlling at $-130 \mathrm{mV}$ (230-130mV). A total of $35.55 \mathrm{million}$ clean reads were generated from three samples, of which 4,820 predicted that open reading frames were annotated. For differential expression analysis, 950 and 1,452 differentially expressed genes were discovered under the conditions of 230-130mV and 120-N, respectively, and the sample 230-N was used as the control. These genes are mainly associated with the pathways of central carbon metabolism and ethanol formation. Increased expression of inulinase and the low activity of the autophagy-related gene, ATG8, ensured fast and ideal fermentation processes.

Conclusions: Despite being reported as the "crabtree-negative" species, K. marxianus Y179 could achieve favorable ethanol fermentation profiles under micro-aeration and high inulin concentrations. K. marxianus Y179 cells responded to inulin concentrations and micro-aeration that is involved in the whole ethanol metabolism network. These results will serve as an important foundation for further exploration of the regulatory mechanisms involved in ethanol fermentation from inulin by consolidated bioprocessing and also provide a valuable reference for future studies on optimization and reconstruction of the metabolism network in K. marxianus.
\end{abstract}

Keywords: Kluyveromyces marxianus, RNA-seq, Ethanol fermentation, Inulin, Transcriptome analysis

\section{Background}

The production of bioethanol from non-grain materials will be an important developmental trend in the fuel ethanol industry, especially in a country like China with a large population and relatively few arable lands. Recently, some inulin-containing materials, especially Jerusalem artichokes, have received increasing attention for their advantages, such as high yield, resistance to poor soil,

\footnotetext{
*Correspondence: ywj@dlut.edu.cn

${ }^{1}$ School of Life Science and Biotechnology, Dalian University

of Technology, Dalian 116024, China

Full list of author information is available at the end of the article
}

drought, low temperatures, and pests [1-3]. Inulin in the roots and tubers of these plants, which is linked by fructose via a $\beta-2,1$ bond [4], is usually regarded as the main carbohydrate for ethanol fermentation.

Kluyveromyces marxianus, a sister species of Kluyveromyces lactis, is another type of "non-conventional" yeast that has been widely studied and has also been reported as a model of "crabtree-negative" yeast, in contrast to Saccharomyces cerevisiae [5]. Due to its high temperature resistance, rapid growth, and capacity to utilize various substrates, there are increasing applications of $K$. marxianus in biofuel industrial biotechnology. Furthermore, 
K. marxianus has been proven to be a key strain that can achieve ethanol fermentation from Jerusalem artichokes by consolidated bioprocessing technology (CBP), which combines inulinase production, inulin hydrolysis, and ethanol production $[2,6,7]$.

The previous results of ethanol fermentation from the inulin of Jerusalem artichokes showed some problems under high inulin concentration conditions, such as residual inulin and a long fermentative time [7]. However, these problems did not happen under micro-aeration or lower inulin concentration conditions (our unpublished data). The molecular mechanisms of the inhibition of higher inulin concentrations and the effects of aeration are still unclear.

Although the whole-genome sequences of $K$. marxianus were first published in 2012 [8], publications on the transcriptional analysis of $K$. marxianus are very limited. Lertwattanasakul et al. [9] conducted complete genome sequencing and transcriptome analyses of $K$. marxianus DMKU 3-1042 to identify genes related to growth at a high temperature and the utilization of various substrates, especially xylose and arabinose. However, there have been no other reports on related information, especially ethanol fermentation by $K$. marxianus.

Considering the preponderance of a low background noise, less amount of RNA required, and the low cost involved in mapping the transcriptome of large genomes [10], in this article, the next-generation sequencing technology for RNA (RNA-seq) was utilized to study the global transcriptional response of $K$. marxianus Y179. The transcriptional response of $K$. marxianus $Y 179$ was studied under various ethanol fermentative conditions [that includes low (12\%) to high (23\%) inulin concentration and in conditions ranging from anaerobic to micro-aeration].

\section{Results and discussion}

Physiological diversity for ethanol fermentation among various $K$. marxianus strains

Though S. cerevisiae has been widely applied in industrial ethanol production, $K$. marxianus is now attracting an increasing amount of attention for its specific physiological diversity. As shown in Table 1, K. marxianus can use multiple substrates, even xylose and lactose, to produce ethanol. Moreover, although $K$. marxianus was known to have a poor ethanol tolerance compared to $S$. cerevisiae [12], the maximum ethanol concentration for $K$. marxianus fermentation broth is more than $100 \mathrm{~g} / \mathrm{L}$. Despite the differences of substrates [6,11-18], the higher specific growth rates of $K$. marxianus guarantee superior results for various fermentative processes.

\section{Ethanol fermentation by $K$. marxianus $Y 179$ from inulin}

Batch fermentation was performed to investigate the differences of gene expression between high and low inulin concentrations and from anaerobic conditions to microaeration. Higher concentrations of inulin repressed the whole process, but aeration promoted it $[19,20]$. Therefore, 120 and $230 \mathrm{~g} / \mathrm{L}$ were selected as low and high inulin concentrations, respectively. An appropriate aeration, by controlling ORP at $-130 \mathrm{mV}$ [19], was set as the aeration condition for transcriptional analysis. The samples were taken at their own end of fermentation to erase the complicated chemical and biological changes that occurred during the fermentation process.

The physiology of ethanol fermentation by $K$. marxianus Y179 under three conditions are shown in Table 1 and Fig. 1. As reported previously [19, 20], K. marxianus Y179 showed obvious catabolite repression under high inulin concentrations. Micro-aeration (ORP $-130 \mathrm{mV}$ )

Table 1 Physiological analysis of ethanol production within different $K$. marxianus strains

\begin{tabular}{|c|c|c|c|c|c|c|c|}
\hline Strains & Substrates & Concentrations (g/L) & Duration (h) & $\mu_{m}\left(h^{-1}\right)$ & $E_{m}(g / L)^{a}$ & $I_{m}(U / m L)^{b}$ & References \\
\hline KM KD-15 & Sucrose + lactose & 200 & 72 & - & 104 & - & {$[11]$} \\
\hline KM UFV-3 & Lactose & 170 & - & - & 80 & - & {$[12]$} \\
\hline KM M15 & Molasses & 150 & 48 & 0.3 & 70 & - & [13] \\
\hline KM DMKU 3-1042 & Cane juice & 220 & 60 & - & 87 & - & {$[14]$} \\
\hline KM CE025 & Glucose + xylose & $28+30$ & 72 & 0.0519 & 12 & - & {$[15]$} \\
\hline KM CBS 7858 & Lactose & 20 & 10 & 0.87 & 6 & - & {$[16]$} \\
\hline KM ATCC 8554 & Inulin & 153 & 60 & - & 61 & 3 & {$[6]$} \\
\hline \multirow[t]{3}{*}{ KM Y179 } & Inulin & 232 & 72 & 0.27 & 93 & 17.5 & This study \\
\hline & Inulin & 227 & 36 & 0.342 & 98 & 22.9 & This study \\
\hline & Inulin & 114 & 24 & 0.474 & 51 & 25.6 & This study \\
\hline \multirow[t]{2}{*}{ KM CBS 6556} & Sucrose & 10 & 9 & 0.7 & - & 1.5 & {$[17]$} \\
\hline & Glucose & 10 & 10 & 0.495 & - & - & [18] \\
\hline
\end{tabular}

\footnotetext{
a Maximum ethanol concentration.
}

b Maximum inulinase activity. 

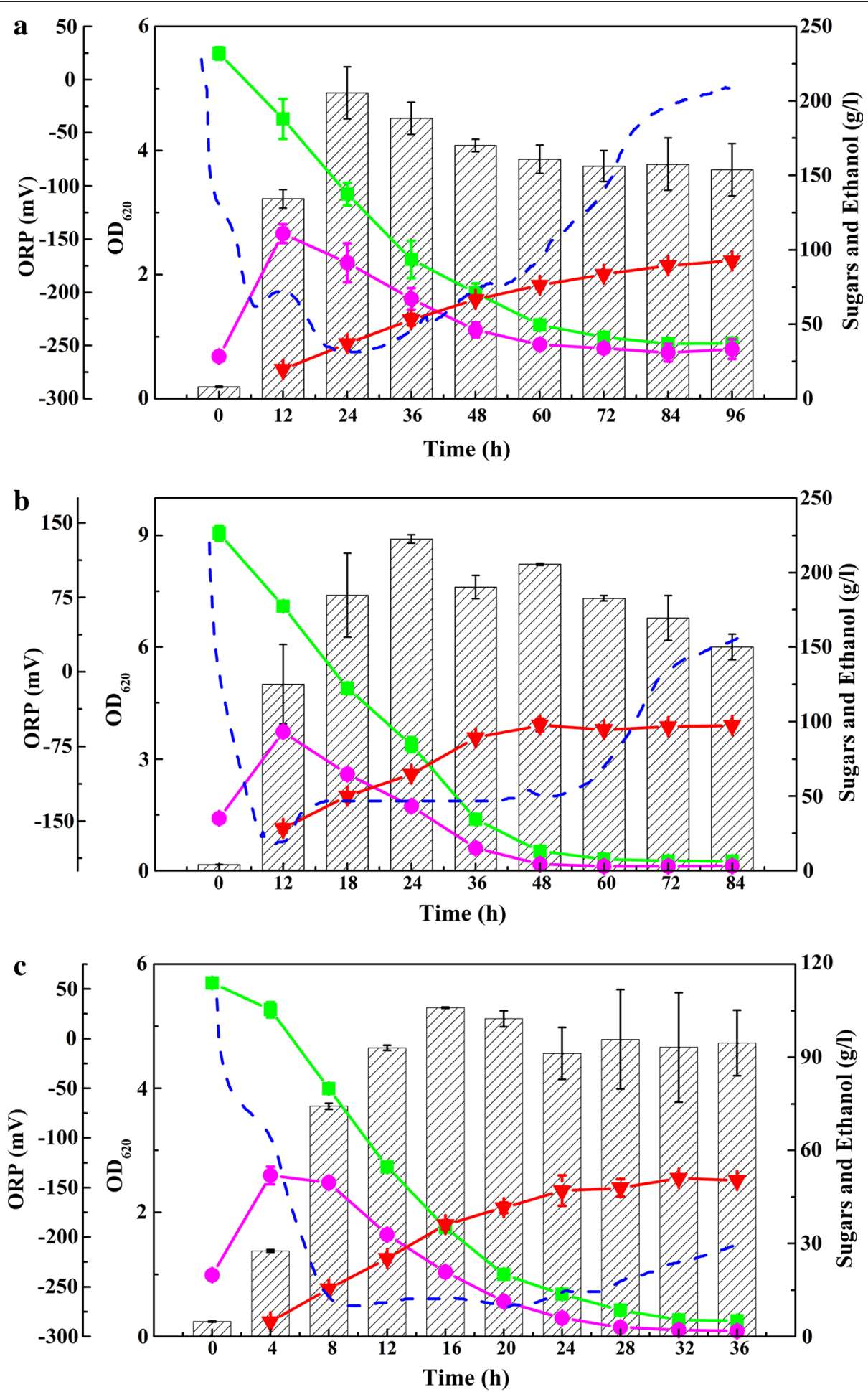

Fig. 1 Profiles of fermentation under three different conditions by K. marxianus. Seed culture (100 mL) was inoculated into a 3-L fermenter with a 1.0-L working volume. a 230-N-72. b 230-130mV-36. c 120-N-24. OD 620 (square with crossed lines), total sugar (green colored square), reducing inulin (purple colored circle) and ethanol (red colored inverted triangle), ORP (blue colored dashed lines). 
allowed $K$. marxianus Y179 to achieve the maximum ethanol concentration from inulin reported so far. The relatively high expression of inulinase by $K$. marxianus Y179 was in accordance with a previous study [20]. Consequently, the transcriptional analysis was conducted to investigate the differences of gene expression between high inulin and low inulin concentrations, and from anaerobic conditions to micro-aeration conditions.

\section{Genome annotation and overall gene expression analysis by RNA-seq \\ Genome annotation}

Genome sequencing of $K$. marxianus had already been completed in 2012 [8]. The $10.9 \mathrm{Mb}$ genome of $K$. marxianus var. marxianus KCTC 17555 (=CBS $6556=$ ATCC 26548) was obtained via the Illumina sequencing platform, which contained $40.1 \%$ guanine and cytosine. Hence, the genome sequence of $K$. marxianus KCTC 17555 was employed as the reference genome for RNAseq in this study. However, no annotation information for $K$. marxianus KCTC 17555 is currently available on the web site, so the genome sequence obtained by Jeong et al. was annotated according to the information from the Gene Ontology (GO) database and the Kyoto Encyclopedia of Genes and Genomes (KEGG) database. The existing genome sequence was integrated into eight chromosomes and the mitochondrial genome. We obtained 2,472 annotations from the GO database, while 1,880 functional genes were obtained from the KEGG database. This annotation information provided a good foundation as a reference for RNA-seq (Table 2).

\section{Overview of transcriptional data by RNA-seq}

After sequencing on the HiSeq 2000 system (Illumina), $1.44 \mathrm{~Gb}$ of raw reads were obtained by RNA-seq from all three samples, subsequently, and 35.55 million cleans reads were acquired after removing the adaptors and the low-quality reads, which accounted for $98 \%$ of the total reads (Additional file 1: Table $\mathrm{S} 1$ ). The clean reads were aligned to the reference genome and genes using the SOAP2 software, with a tolerance of no more than $2 \mathrm{bp}$ mismatches. The number of reads that uniquely mapped the reference genome and genes accounted for $\sim 74-89 \%$ and $\sim 35-57 \%$, respectively (Additional file 1: Table S1).

\section{Quantification analysis of gene expression from $K$. marxianus $\mathrm{Y} 179$}

\section{Overall differential gene expression and validation by $q P C R$}

The levels of gene expression, normalized as reads per kilobase per million mapped reads (RPKM), were applied to the fold changes of the differentially expressed genes (DEGs). The annotated genes were able to be covered by the clean reads from RNA-seq, $\sim 66-93 \%$ of which achieved over a $90 \%$ coverage of the known genes (Fig. 2a).

Two comparison modules among the three samples, $230-130, \mathrm{mV}-36$ vs $230-\mathrm{N}-72$, and $120-\mathrm{N}-24$ vs $230-\mathrm{N}-$ 72 , were performed to investigate the significantly differentially expressed genes between micro-aeration and hypoxic conditions, or between low and high inulin concentrations (Additional file 1: Figure S1). In the first module, of 1,840 DEGs, 950 genes had annotation information, including 696 genes from KEGG and 520 genes from GO, when setting the cutoff values of screening as FDR $\leq 0.001$ and the absolute value of $\log 2$ ratio $\geq 1$. In the other module, 1,452 of 2,658 DEGs were obtained with annotation information, including 1,095 genes from KEGG and 820 genes from GO. Thus, it could be seen that, compared with aeration and hypoxic conditions, a larger difference in gene expression between low and high inulin concentrations were observed during ethanol production by $K$. marxianus Y179.

A further statistical analysis of genes containing annotations in the two modules is illustrated in Fig. $2 b-d$, which showed that 497 mutual genes changed between two modules. Considering the up- or down-regulation of genes, it was remarkable that a great deal of genes were up-regulated (including genes related to ethanol metabolism, transcriptional factors, and so on) in the module of $120-\mathrm{N}-24$ vs 230-N-72, which might explain the inhibition of high inulin concentrations (Fig. 2c). The distribution of RPKM in $230-130 \mathrm{mV}-36$ vs $230-\mathrm{N}-72$ was slightly higher than that of $120-\mathrm{N}-24$ vs $230-\mathrm{N}-72$, which might be due to the fewer DEGs in the module of $230-130 \mathrm{mV}-36$ vs $230-\mathrm{N}-72$.

Six genes involved in various pathways were selected to conduct the qPCR experiments to validate the reliability of data from RNA-seq. As illustrated in Table 3, though there were a few differences between the fold changes of RNA-seq and qPCR, the trends of up- or down-regulation of all six genes chosen were the same, which consequently demonstrated the accuracy of the trends of gene expression change obtained by RNA-seq.

\section{Characterization of DEGs involved in central carbon metabolism}

Of 1,880 genes containing KEGG annotations in $K$. marxianus Y179, more than 88 KEGG metabolic pathways were categorized; 35 and 56 DEGs (fold-change $\geq 2$ ) were related to the central carbon metabolic pathways (glycolysis/gluconeogenesis, TCA cycle, and PPP) or $230-130 \mathrm{mV}-36$ vs $230-\mathrm{N}-72$ and $120-\mathrm{N}-24$ vs $230-\mathrm{N}-$ 72 , respectively. According to these KEGG pathways, we reconstructed the metabolic network containing the central carbon metabolic pathway, ethanol and glycerol formation pathways, and the related intermediate enzymes (Figs. 3, 4). 
Table 2 Overview of genomes of K. marxianus KCTC 17555 and annotations by GO and KEGG databases

\begin{tabular}{|c|c|c|c|c|c|c|c|c|}
\hline & \multirow[t]{2}{*}{ Length (Mb) } & \multirow[t]{2}{*}{ CDS (GO) } & \multicolumn{2}{|l|}{ CDS (KEGG) } & \multicolumn{4}{|c|}{ CDS length (bp) } \\
\hline & & & With annotation & Without annotation & 500 & $501-1,000$ & $1,001-2,000$ & 2000 \\
\hline Total & 10.9 & 2,472 & 1,880 & 2,940 & 447 & 1,246 & 2,003 & 1,123 \\
\hline Average & & & & & $1,530$. & & & \\
\hline Chromosome 1 & 1.7 & 411 & & & & & & \\
\hline Chromosome 2 & 1.7 & 407 & & & & & & \\
\hline Chromosome 3 & 1.5 & 333 & & & & & & \\
\hline Chromosome 4 & 1.4 & 308 & & & & & & \\
\hline Chromosome 5 & 1.3 & 308 & & & & & & \\
\hline Chromosome 6 & 1.1 & 276 & & & & & & \\
\hline Chromosome 7 & 0.9 & 209 & & & & & & \\
\hline Chromosome 8 & 0.9 & 211 & & & & & & \\
\hline Mitochondrion & 0.4 & 9 & & & & & & \\
\hline
\end{tabular}

Inulinase encoded by INU1 in K. marxianus Y179 might, to a large extent, affect the sugar consumption rates in ethanol fermentation. Compared with 230$\mathrm{N}-72$, micro-aeration $(230-130 \mathrm{mV}-36)$ and low inulin concentration (120-N-24) up-regulated INU1 by 1.14and 1.94-fold, respectively, which was in accord with the inulinase activities of the supernatants (Table 1) and the previously published results $[19,20]$. Hexokinase and glucokinase, encoded by $H X K 1$ and GLK1, respectively, which are crucial enzymes for controlling glucose and fructose in the central carbon metabolic pathway, were overexpressed by 2.2- and 3.0-fold under micro-aerobic and low inulin conditions in our systems, respectively. The overexpression of these three genes might explain the phenomenon of fast inulin consumption rates.

Phosphoglycerate mutase (encoded by GPM1) catalyzed the transition between 2-phosphoglycerate and 3-phosphoglycerate. Three kinds of isozymes were found in S. cerevisiae, encoded by GPM1, GPM2, and GPM3 [21, 22]. Gpm1p and Gpm3p were detected in K. marxianus Y179, the identities of which were 87 and $57 \%$, respectively, in contrast to that in S. cerevisiae. The expression of GPM1 under aerobic and low inulin conditions was down-regulated by 1.89 - and 2.83-fold, respectively. Papini et al. [23] also made it clear that the GPM1 of S. cerevisiae were substantially up-regulated when using ethanol as the only carbon source. Consequently, the differential expression of GPM1 in K. marxianus Y179 was inferred to be associated with respiratory growth on non-fermentable substrates, like ethanol, to maintain the energy balance in the central carbon metabolic pathway. To enhance a high ethanol yield, silencing GPM1 in K. marxianus Y179 is an apparent alternative option to decrease the loss of ethanol as the substrate.

Pyruvate is the pivotal intermediate metabolite of the entire central carbon metabolism and determines the carbon fluxes to the TCA cycle or to ethanol formation. Pyruvate kinase, which catalyzes phosphoenolpyruvate into pyruvate, is regarded as the rate-limiting enzyme. Two kinds of pyruvate kinases, Pyk1p and Pyk2p (encoded by $C D C 19$ and $P Y K 2$, respectively), have been observed in S. cerevisiae so far [24, 25]. It was indicated previously that the expression of Pyk1p had nothing to do with the accumulation of ethanol [26], but it might be concerned with glucose utilization under the conditions of high temperature or resistance to environmental stress [24]. Only one kind of pyruvate kinase was detected in K. marxianus Y179, KmPyk1p, the identity of which was $86 \%$ homologous with Pyk1p in S. cerevisiae. However, the expressions of KmPYK1 under three conditions demonstrated few differences (Additional file 1: Table S2).

To our surprise, the expression of malate dehydrogenase (Mdh1p) in the sample of $230-130 \mathrm{mV}-36$ increased by up to 4.6 -fold. The enhanced transcription of mdh1p, a key enzyme in the TCA cycle, might be speculated to have other biological functions, because there was no obvious enhancement of the TCA cycle in $230-130 \mathrm{mV}$ 36. Previous results showed that $M D H$ could be regarded as a transhydrogenase-like shunt, which regulated the redox state in S. cerevisiae cells [27]. What is more important, research from Lushchak et al. [28] indicated that the expression level of Mdh1p in SOD-defective S. cerevisiae was up-regulated to work as a protective mechanism under oxidative stress. Consequently, the up-regulation of KmMDH1 in 230-130mV-36 might have 


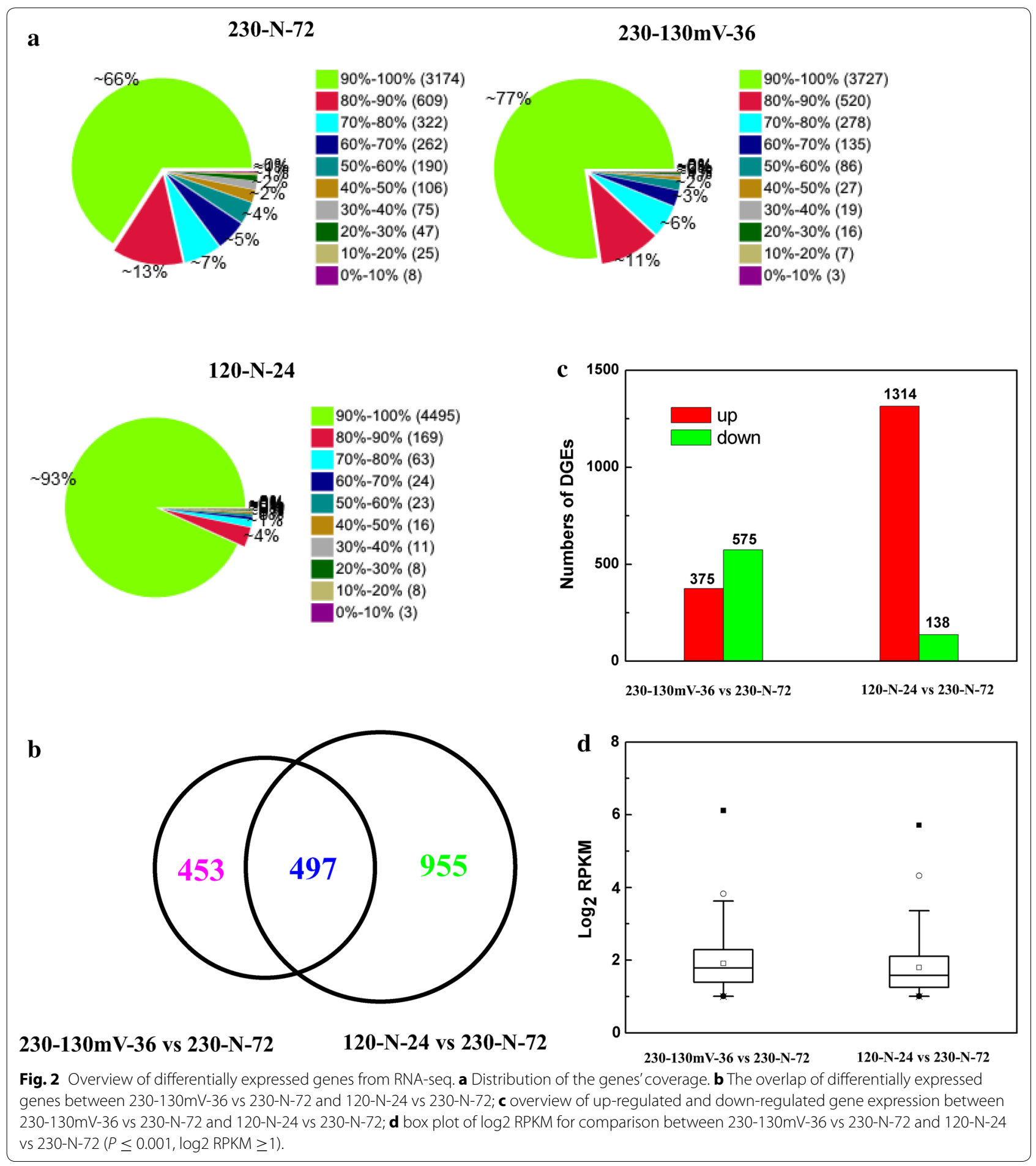

something to do with this. On the other hand, PPP provided and balanced $\mathrm{NADP}^{+} / \mathrm{NADPH}$ or $\mathrm{NAD}^{+} / \mathrm{NADH}$ ratio in cells, so the expression of genes involved in PPP were promoted under aerobic conditions $(230-130 \mathrm{mV}$ 36) for the regulation and balance of the redox state in the cell (Figs. 3, 4).

\section{Characterization of DEGs related to ethanol, glycerol,}

\section{and by-products formation}

Pyruvate was first converted to acetaldehyde by pyruvate decarboxylase (pdc), which was then reduced to ethanol by alcohol dehydrogenase (adh) in the pathway of ethanol formation. The pyruvate decarboxylase, $P D C 1$, played 
Table 3 Comparison of change folds in DEGs between RNA-seq and qPCR

\begin{tabular}{|c|c|c|c|c|c|c|}
\hline \multirow[t]{2}{*}{ No. } & \multirow[t]{2}{*}{ Gene } & \multirow[t]{2}{*}{ Gene ID } & \multicolumn{2}{|l|}{ RNA-seq } & \multicolumn{2}{|l|}{ qPCR } \\
\hline & & & 230-130mV-36/230-N-72 & $120-\mathrm{N}-24 / 230-\mathrm{N}-72$ & 230-130mV-36/230-N-72 & $120-\mathrm{N}-24 / 230-\mathrm{N}-72$ \\
\hline 1 & INU1 & allA4270 & 2.21 & 3.85 & 1.52 & 1.81 \\
\hline 2 & FBP1 & allA1368 & 1.20 & 69.32 & 0.40 & 37.25 \\
\hline 3 & HXK1 & allA0887 & 4.57 & 8.24 & 4.84 & 4.28 \\
\hline 4 & CTT1 & allA1698 & 19.18 & 4.01 & 9.43 & 1.74 \\
\hline 5 & GPM1 & allA4044 & 0.27 & 0.14 & 0.09 & 0.04 \\
\hline 6 & GDP1 & allA4645 & 0.06 & 0.96 & 0.05 & 0.40 \\
\hline
\end{tabular}

a crucial role in the decarboxylation of pyruvate in cells, and the expression of PDC1 in high ethanol concentrations (230-N-72 and 230-130mV-36 against $120-\mathrm{N}-24$ ) was enhanced by roughly threefold, which agreed with previous results [26]. In addition, an appropriate aeration resulted in a slightly higher RPKM value of PDC1 (25,820 vs 22,334). As mentioned by Suleau et al. [5], the up-regulation of $P D C 1$ ensured carbon fluxing to the fermentative pathways rather than the TCA cycle, which indicated the relatively ideal results of micro-aeration by controlling ORP at $-130 \mathrm{mV}$.

Acetaldehyde is reversibly reduced to ethanol by alcohol dehydrogenase, which is a vital enzyme for the metabolism of ethanol in yeasts. At least seven kinds of alcohol dehydrogenase were found in S. cerevisiae, Adh1p-Adh7p [29]. Seven alcohol dehydrogenases detected in $K$. marxianus Y179 were analyzed using a phylogenetic tree (Fig. 5). The levels of expression (RPKM values) demonstrated the remarkable functions of four $A D H$ genes (Adh1p-Adh4p), which could be classified into two types according to the phylogenetic tree. Adh1p and Adh2p were found to be located in the cytosol, were the main functional alcohol dehydrogenases under anaerobic conditions, and kept a high transcriptional level under very high gravity conditions [26, 30], which was in accordance with our results in this article. Additionally, Adh3p and Adh4p were located in the mitochondria. Adh4p showed no structural or functional homologies with the other three enzymes [29], and its low RPKM value obtained in this study demonstrated a small role in ethanol metabolism in the presence of nonrespiratory carbon sources, as described previously [31]. As reported previously, ADH3-disrupted $K$. marxianus was more sensitive to the reactive oxygen species [31]. The expression of $A D H 3$ in K. marxianus Y179 was dramatically up-regulated (over 10-fold) under aerobic conditions (230-130mV-36 against 230-N-72 and 120-N-24) (Fig. 5; Additional file 1: Table S2), which hence participated in the enhancement of respiration and played a significant role in the reduction reactions.
Glycerol, as a protective mechanism responding to environmental stress, played a key role in keeping high cell viabilities during ethanol fermentation. Two homologies of glycerol-3-phosphate dehydrogenase, key enzymes in glycerol metabolism, were discovered in S. cerevisiae (Gpd1p and Gpd2p), which exhibited an enhanced expression under high osmolarity and anaerobic conditions, respectively [32-34]. Our results revealed that there were also two kinds of glycerol-3-phosphate dehydrogenase in K. marxianus Y179, KmGpd1p and KmGpd2p. GPD1 from S. cerevisiae was reported to be significantly down-regulated, due to a lack of dissolved oxygen [26]; however, in our study, the KmGPD1 gene was apparently up-regulated under high inulin concentrations and anaerobic conditions (Additional file 1: Table S2), which agreed with the concentration obtained by HPLC in the supernatant (data not shown).

\section{Characterization of DEGs response to oxidative stress}

Our previous fermentation indicated the delay of the process under relatively anoxic conditions and in turn an appropriate aeration volume promoted cell growth and ethanol production. From yet another angle, aeration resulted in the production of toxic compounds, called reactive oxygen species (ROS), including superoxide, peroxide, hydroxyl radical, and so on $[35,36]$. As a consequence, a thorough protective mechanism exists in $K$. marxianus Y179 cells to protect it from damage by ROS.

The Trx-TrxR system is widely present in most yeast mitochondria and acts as a defense against ROS damages. Under aerobic conditions, the TRXR gene increased by 1.0-fold (230-N-72) and 3.4-fold (120-N-24), respectively. Glutathione reductase achieved the transition between oxidized and reduced glutathione, which was up-regulated by 1.5 - to 2.4-fold under aerobic conditions. Peroxidase consumed ROS like $\mathrm{O}_{2}{ }^{2-}$ via the reduction of $\mathrm{H}_{2} \mathrm{O}_{2}$, which mainly includes catalase and glutathione peroxidase, and aeration enhanced them by 2.2- to 4.3-fold (230-N-72) and 2.3 - to 2.6-fold (120-N-24), respectively. $\mathrm{Cu}-\mathrm{Zn}$ superoxide dismutase was also up-regulated by roughly 1.0 -fold 


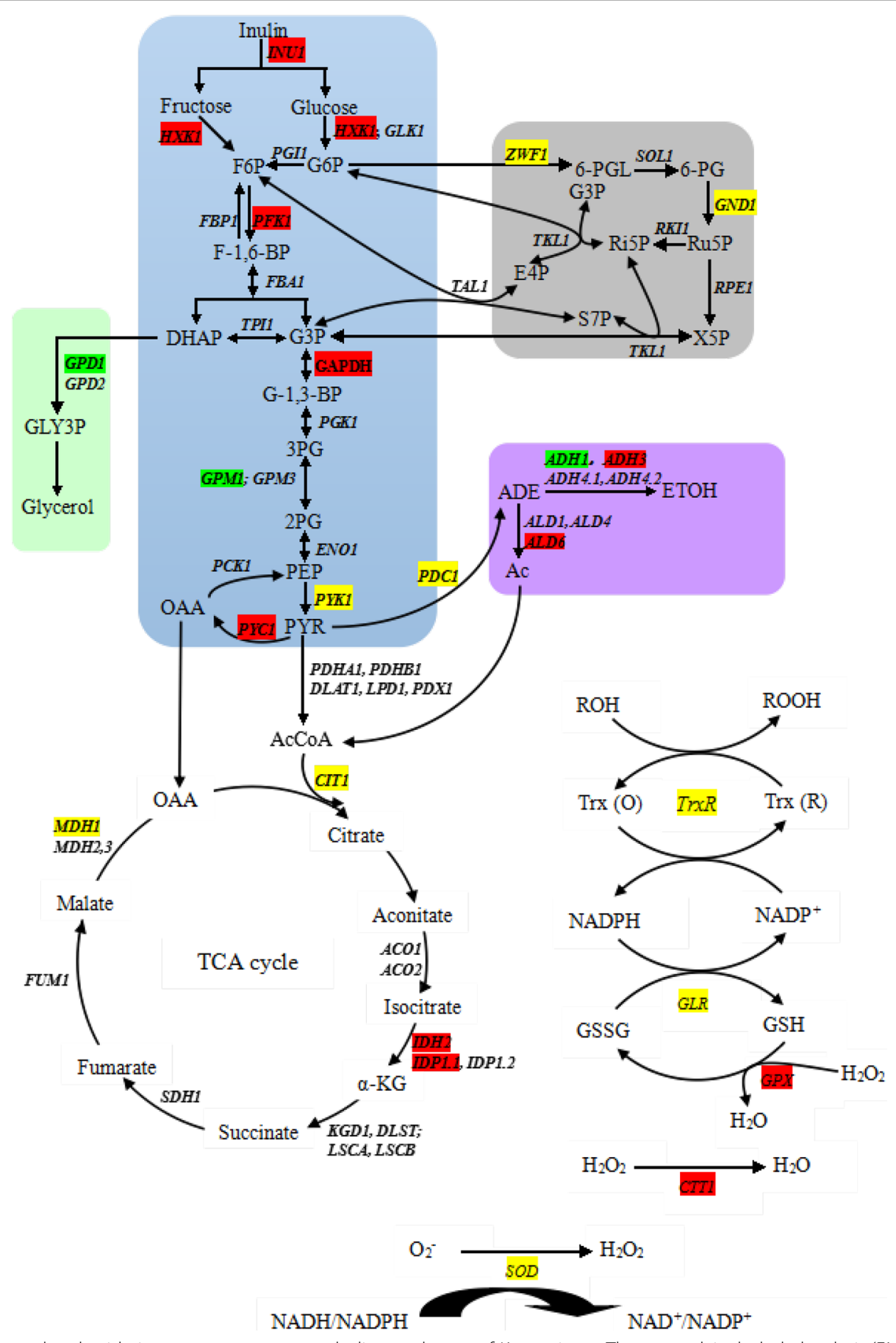

Fig. 3 Profiles of central and oxidative stress response metabolism pathways of K. marxianus. The network included glycolysis (EMP), the ethanol and glycerol formation pathway, the TCA cycle, the pentose phosphate pathway (PPP), and the oxidative stress response pathway. Genes marked in red, green, and yellow represented up-regulated, down-regulated, or a mixture of up-regulated and down-regulated RPKMs, respectively, in 230-N72, 230-130mV-36 and 120-N-24 conditions. Further details are given in Table 5.

under aerobic conditions to remove the superoxide anion in cells. Blanco et al. [35] reported the responses of gene transcriptional levels in $K$. lactis to hypoxic and oxidative stress, and they found that the TRXR and CTT1 genes in wild-type $K$. lactis were obviously up-regulated during the aerobiosis-hypoxia shift. In spite of ROS being generated 


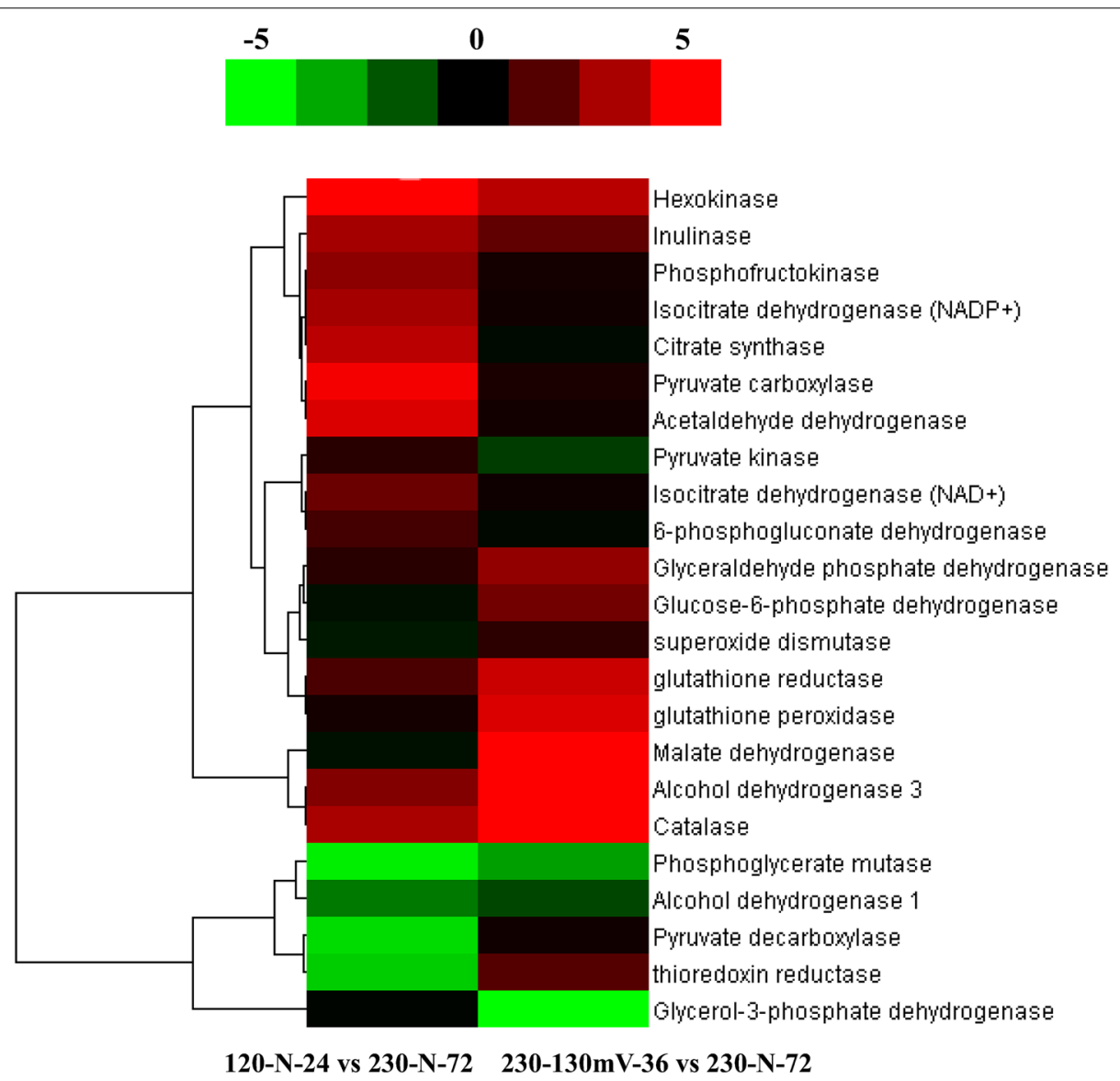

Fig. 4 Cluster analyses of key genes from central and oxidative stress response metabolism pathways. Differentially expressed genes were clustered by log2-based expression values; the rows indicate different genes and the columns indicate two comparisons. Green, black, and red indicate upregulated, unchanged, and down-regulated genes, respectively.

by aeration (230-130mV-36), the obvious up-regulation of various genes related to oxidative stresses removed most ROS damages and guaranteed relatively high cell viabilities to achieve an ideal result.

A type of alkyl hydroperoxide reductase (encoded by KmallA2475) was worthy of attention because of its high transcriptional level (RPKM up to 20,000), which increased by 1.3- to 3.3-fold compared to that under anoxic conditions. On the basis of sequence analysis, it belonged to one of the five types of peroxiredoxin (Tas1p) [37], which occupied the highest concentration in cells [38]. The homologous identity of KmallA2475 with that in S. cerevisiae was up to $90 \%$, and it could be predicted that KmallA2475 in $K$. marxianus Y179 might be one of the most important enzymes for defense against ROS damages.

In addition, the high transcriptional level of a polyamine transporter (encoded by TPO1) piqued our interests (Additional file 1: Table S2). Endogenous polyamine protects cells from damage by some fermentation inhibitors and ethanol by binding to plasma membranes, ribosomes, and DNA [39]. Aranda et al. [40] found that the addition of acetaldehyde upregulated TPO1 in S. cerevisiae. Moreover, a TPO1defective strain showed an enhanced tolerance of fermentation inhibitors, such as furfural and acetic acid [41]. However, the aerobic conditions increased the TPO1 gene expression by 2.6- to 3.7 -fold accordingly in our study. Though the specific underlying reasons and mechanisms are still unclear, we predict that this may be related to the acetaldehyde content in ethanol metabolism and that it may belong to a kind of protective mechanism for cells, especially for defending against damages by ROS from aeration by transporting a special type of polyamine into cells. 


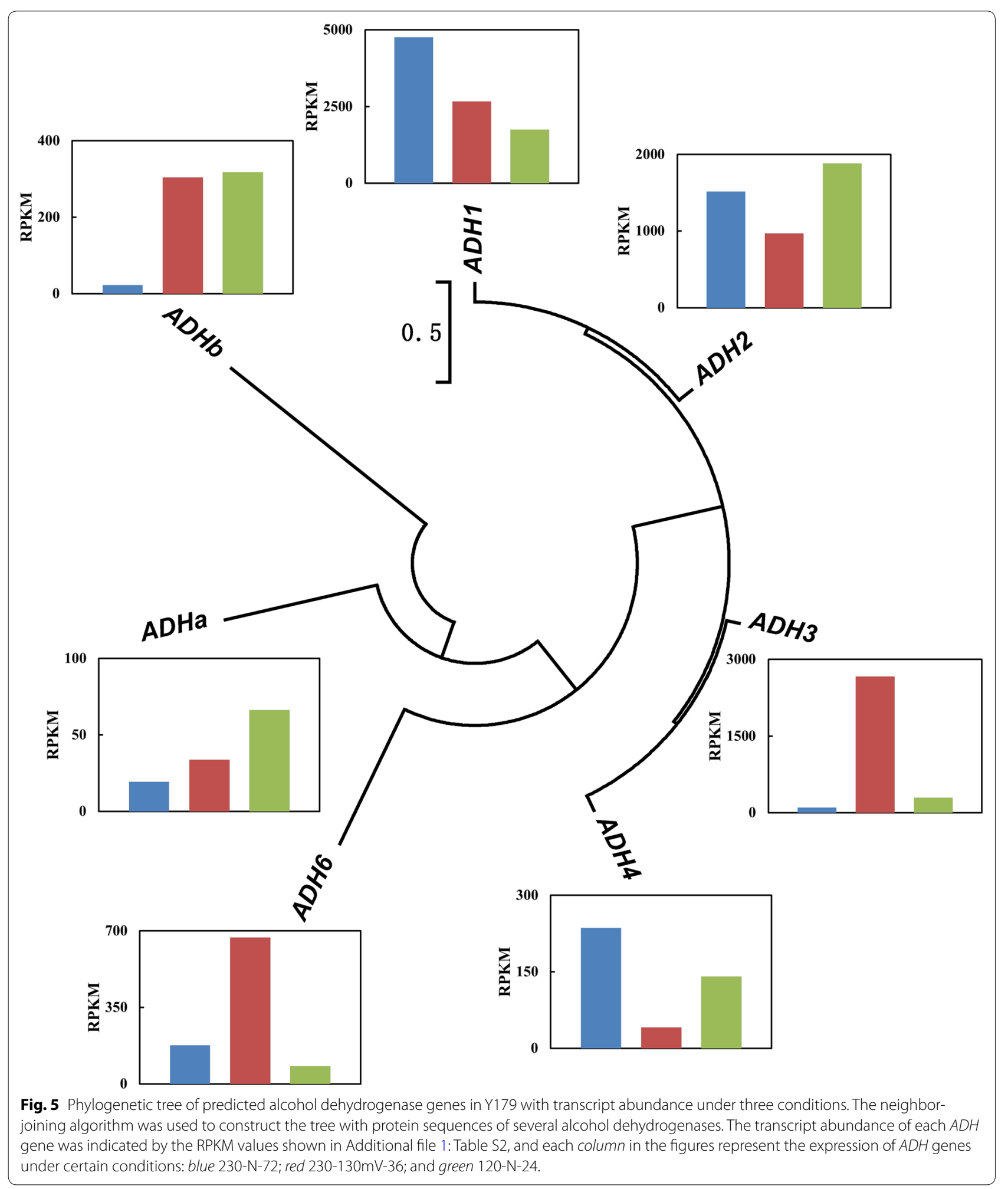

\section{Characterization of DEGs associated with sugar}

\section{transporters}

Considering the homology between $K$. marxianus and $K$. lactis, we aligned the predicted hexose transporter genes in K. marxianus Y179 to the known transporters in $K$. lactis and obtained a similar transport system (Table 4). K. lactis embraced a relatively simple transport system and related genes [42]. The transport of 
Table 4 Hexose transporters in K. lactis and K. marxianus

\begin{tabular}{|c|c|c|c|c|c|c|}
\hline \multirow[t]{2}{*}{ Transporter in $K L$} & \multirow[t]{2}{*}{ Functions } & \multirow[t]{2}{*}{ Gene in $K M$} & \multirow[t]{2}{*}{ Identities (\%) } & \multicolumn{3}{|l|}{ RPKM } \\
\hline & & & & 230-N-72 & 230-130mV-36 & $120-\mathrm{N}-24$ \\
\hline \multirow[t]{2}{*}{ RAG1/KHT1 } & \multirow[t]{5}{*}{ Low-affinity glucose transporter } & KMallA1640 & 79 & 243.57 & 149.56 & 629.7 \\
\hline & & KMallA1641 & 78 & 337.99 & 27.69 & 112.28 \\
\hline \multirow[t]{3}{*}{ KHT2 } & & KMallA1637 & 83 & 111.28 & 65.63 & 138.4 \\
\hline & & KMallA1638 & 82 & 238.77 & 126.54 & 317.6 \\
\hline & & KMallA1639 & 80 & 127.34 & 282.86 & 350.28 \\
\hline HGT1 & High-affinity glucose transporter & KMallA4236 & 80 & 111.48 & 62.78 & 762.2 \\
\hline FRT1 & High-affinity fructose transporter & KMallA0822 & 79 & 194.02 & 103.62 & 745.55 \\
\hline
\end{tabular}

hexoses by $K$. lactis mainly relied on two transporters: a low-affinity glucose transporter, rag1p [43], and a highaffinity glucose transporter, hgt1p [44]. In most $K$. lactis cells, rag1p was usually replaced by two high homologous proteins, Kht1p and Kht2p [42]. In addition, K. lactis also expressed the FRT1 gene, which encoded a hexose transporter with a high affinity with fructose, which contributed to parts of hexose transport [45].

Rag1p/kht1p in $K$. marxianus Y179 was induced by high concentrations of glucose or fructose, and we detected two predicted open reading frames (ORFs) that encoded the protein (KmallA1640 and KmallA1641). Kht2p, encoded by three ORFs (KmallA1637, KmallA1638, and KmallA1639), was up-regulated under low glucose concentrations. The up-regulation of two high-affinity transporters, Hgt1p and Frt1p, in the sample of $120-\mathrm{N}-24$ might account for the low residual sugar concentration. Therefore, we speculated that if the expression of these transporters were increased at the first stage of fermentation, the process of ethanol production might be accelerated to some extent.

\section{Characterization of DEGs referring to transcriptional regulations}

Transcriptional regulation may be associated with transcription factors (TFs). The phenomenon of glucose repression exists widely in yeast cells, where mig1p, encoded by MIG1, may be a crucial TF. The MIG1 gene had been detected in various yeasts, including $S$. cerevisiae, $K$. lactis, and $K$. marxianus [46, 47]. Cassart et al. [47] demonstrated that the expression of MIG1 was regulated by glucose in the media, and the promoters of invertase (encoded by SUC2) and inulinase (encoded by INU1) were repressed by Mig1p in the presence of glucose. In our experiments, the enhanced expression of KmMIG1 was observed under high inulin and anoxic conditions ( $\mathrm{RPKM}=1,308$, Additional file 1: Table S2). After the employment of low inulin and aerobic conditions, the expression of KmMIG1 was down-regulated by
1.4- to 2.5-fold. Consequently, an appropriate manipulation of the MIG1 gene (for example, lowering or silencing its expression at the initial stage of fermentation) may improve some key enzymes' activities, like inulinase in the process of ethanol production from inulin, thus fundamentally solving the complex problems.

In contrast to the behavior of $M I G 1$, the CCR4/POP2 regulation system contributes to glucose derepression. Ccr4p is a complex that regulates the expression of various genes in yeast cells. Known to be part of the Ccr4p complex [48, 49], similar to that of Pop2p, Ccr4p can resist glucose repression with the assistance of glucoserepressible alcohol dehydrogenase (encoded by AHD2) [49]. The relatively low transcriptional levels of the two TFs in K. marxianus Y179 (KmPOP2 and KmCCR4), which were homologous to those in S. cerevisiae, indicated that the CCR4/POP2 system did little to regulate gene expression in $K$. marxianus Y179. The inconspicuous differences in the expression of $A D H 2$ among three samples had also proven the above conclusion (Fig. 5; Additional file 1: Table S2).

On the other hand, the expression of some functional proteins will also affect the gene expression and the maintenance of their activities. The heat shock protein $(H S P)$ family is a family of chaperones that assist proteins to fold correctly and maintain activities under some strict environmental stresses. Hsp26 had a very high transcriptional level in $K$. marxianus Y179 during ethanol fermentation, up to $53 \%$ compared to that in S. cerevisiae, which was one of the ten highest expressed genes in all three samples (Additional file 1: Table S2). Amorós et al. [50] discovered that HSP26 in S. cerevisiae was up-regulated under carbon source starvation and oxidative and osmotic stresses. As a consequence, it can be inferred that the enhanced expression of KmHSP26 in K. marxianus Y179 may be related to the low inulin and high ethanol conditions at the final stage of fermentation.

Hsp42 was also previously reported in $S$. cerevisiae under ethanol fermentation conditions [26]. The 
expression profile of Hsp42 was also found to be correlated with an increase in ethanol concentrations, and its expression was induced by high ethanol concentrations, which was consistent with our results in this article. A 1.0-fold up-regulation of KmHSP42 expression was observed under high ethanol and anoxic conditions (Additional file 1: Table S2), which might be conducive to conserving the enzyme activities of cells under very high ethanol concentrations. Hsp31 was induced by increasing oxidative stress in S. cerevisiae [51]. In accordance with that, we found that KmHSP31 was up-regulated by 2.7- to 3.6-fold under aerobic conditions (230-130mV-36) in contrast to those in anoxic conditions, which might reduce the damages of enzymes in cells under high oxidative stress.

\section{Characterization of DEGs related to autophagy}

Autophagy is supposed to be a conserved catabolic process in eukaryotes to maintain a steady state by the degradation of damaged cellular organelles and other dysfunctional macromolecules, like proteins [52]. Autophagy has been proven to make great differences and to guarantee the survival of yeasts under various stressful conditions [53]. There were great differences observed between the viability of cells under three conditions (Fig. 6a), which might result in different fermentative profiles. It was inferred that cell viabilities were greatly related to the fermentation time and the residual sugar concentration at the end. Consequently, having a better understanding of DEGs related to autophagy may provide references for optimizing the fermentative process.

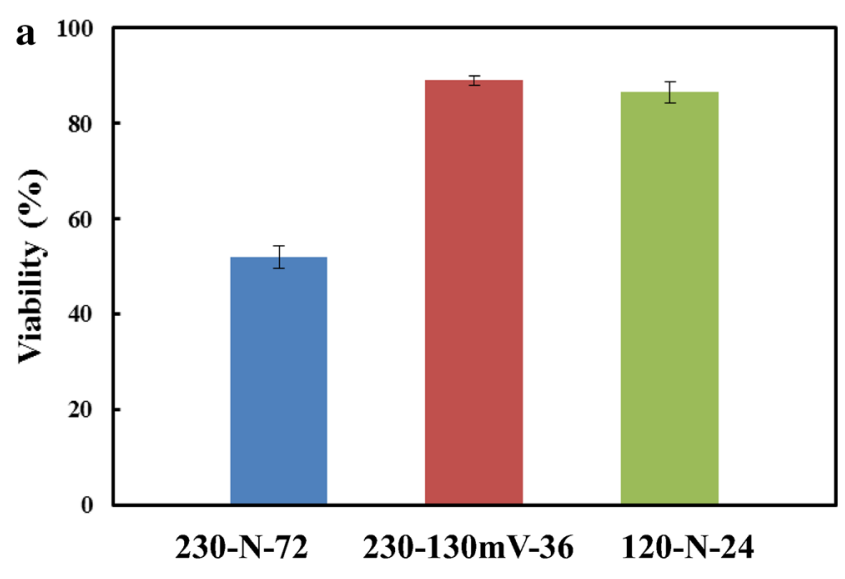

b

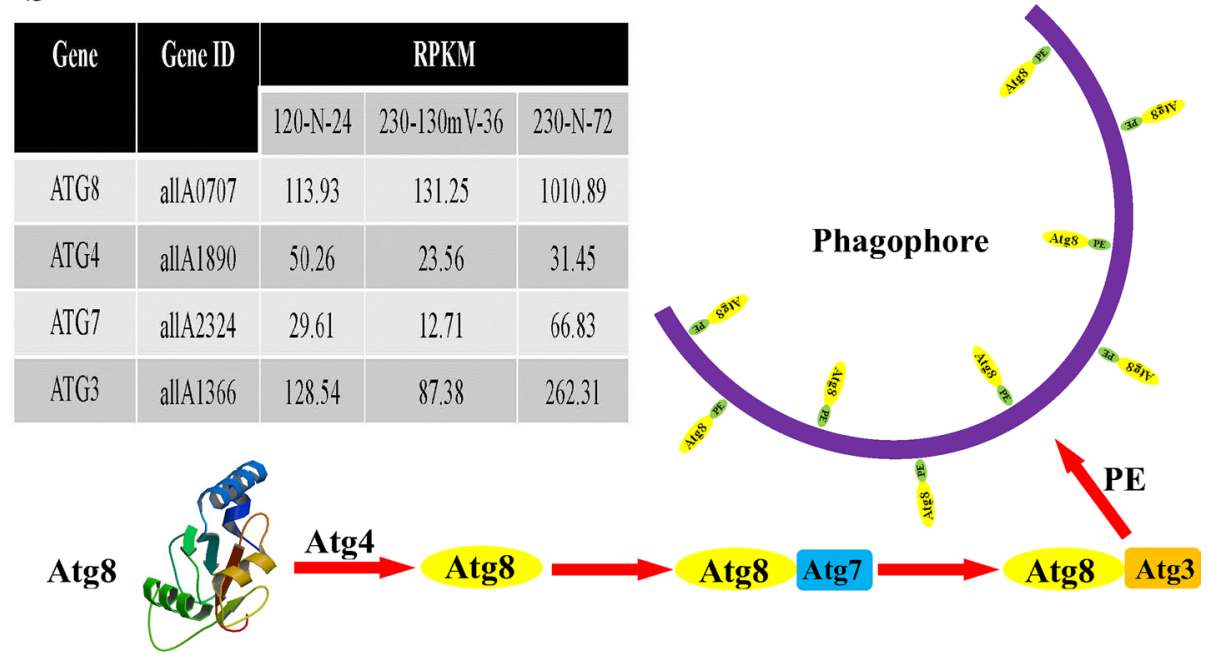

Fig. 6 Profile of gene expression related to cell viability and non-selective autophagy in K. marxianus Y179. a Cell viabilities of three conditions at their own fermentative terminal. b Transcript abundance of ATG genes related to non-selective autophagy in K. marxianus Y179 and a brief introduction to the mechanism of non-selective autophagy. 
It was detected that non-selective autophagy played a vital role for maintaining the cell survival in the systems of ethanol production from inulin by K. marxianus Y179 (Fig. 6). Non-selective autophagy, also called macroautophagy, engulfs the cytoplasm to form autophagosomes, which comprise the main degradation process in eukaryotes [54]. Three DEGs related to autophagy, ATG3, ATG7, and $A T G 8$ (Fig. 6b; Table 5), were identified to contribute to the formation of autophagosomes [55]. Atg8, a ubiquitin-like protein, was up-regulated by almost 3.0-fold under the condition of 230-N-72, which was in line with the results of cell viabilities (Fig. 6a). Moreover, it was reported that when macroautophagy occurred in cells, the expression of ATG8 would greatly increase to demonstrate a positive correlation with the size of autophagosomes $[55,56]$. Hence, the expression of ATG genes

Table 5 General review of autophagy-related genes (ATG) in K. marxianus

\begin{tabular}{|c|c|c|c|c|c|c|}
\hline \multirow[t]{2}{*}{ Gene } & \multirow[t]{2}{*}{ Gene ID } & \multirow[t]{2}{*}{ Size (bp) } & \multicolumn{3}{|l|}{ RPKM } & \multirow[t]{2}{*}{ Source } \\
\hline & & & $120-\mathrm{N}-24 \mathrm{~h}$ & $230-130 \mathrm{mV}-36 \mathrm{~h}$ & $230-\mathrm{N}-72 \mathrm{~h}$ & \\
\hline ATG1 & allA2788 & 2,511 & 251.63 & 168.95 & 164.18 & This study \\
\hline ATG2 & allA1909 & 4,500 & 53.51 & 32.78 & 34.03 & This study \\
\hline ATG3 & allA1366 & 927 & 128.54 & 87.38 & 262.31 & This study \\
\hline ATG4 & allA1890 & 1,356 & 50.26 & 23.56 & 31.45 & This study \\
\hline ATG5 & allA3366 & 816 & 20.84 & 3.60 & 2.45 & This study \\
\hline ATG6 & allA1725 & 1,401 & 36.51 & 6.98 & 15.84 & This study \\
\hline ATG7 & allA2324 & 1,821 & 29.61 & 12.71 & 66.83 & This study \\
\hline ATG8 & allA0707 & 375 & 113.93 & 131.25 & 1010.89 & This study \\
\hline ATG9 & allA0163 & 2,721 & 34.98 & 6.23 & 11.46 & This study \\
\hline ATG10 & KLMA_80409 & 444 & $\mathrm{BAO} 42720.1^{\mathrm{a}}$ & & & \\
\hline ATG11 & allA0263 & 3,255 & 85.22 & 11.92 & 34.94 & This study \\
\hline ATG12 & None $^{b}$ & & & & & \\
\hline ATG13 & allA2363 & 2,139 & 97.01 & 188.12 & 249.63 & This study \\
\hline ATG14 & KLMA_20709 & 918 & BAO39167.1 & & & \\
\hline ATG15 & allA2983 & 1,635 & 128.96 & 96.59 & 51.56 & This study \\
\hline ATG16 & allA3834 & 381 & 21.74 & 20.96 & 21.60 & This study \\
\hline ATG17 & allA4154 & 1,266 & 19.40 & 10.68 & 8.08 & This study \\
\hline ATG18 & KLMA_20474 & 1,542 & BAO38932.1 & & & \\
\hline ATG19 & allA2869 & 1,743 & 76.03 & 36.47 & 64.82 & This study \\
\hline ATG20 & allA0816 & 1,803 & 113.96 & 110.55 & 640.71 & This study \\
\hline ATG21 & allA4285 & 1,185 & 75.91 & 34.11 & 20.63 & This study \\
\hline ATG22 & KLMA_10053 & 1,491 & BAO37675.1 & & & \\
\hline ATG23 & allA1449 & 1,329 & 49.09 & 21.95 & 74.88 & This study \\
\hline ATG24/SNX4 & allA2880 & 1,194 & 46.00 & 13.79 & 23.39 & This study \\
\hline ATG25 & None & & & & & \\
\hline ATG26 & allA4736 & 3,696 & 432.33 & 104.68 & 251.49 & This study \\
\hline ATG27 & allA4445 & 840 & 60.38 & 29.88 & 140.73 & This study \\
\hline ATG28 & None & & & & & \\
\hline ATG29 & KLMA_30451 & 489 & BAO39746.1 & & & \\
\hline ATG30 & None & & & & & \\
\hline ATG31 & None & & & & & \\
\hline ATG32 & allA3211 & 1,542 & 87.64 & 24.42 & 135.53 & This study \\
\hline ATG33 & None & & & & & \\
\hline ATG34 & None & & & & & \\
\hline ATG35 & None & & & & & \\
\hline ATG36 & None & & & & & \\
\hline
\end{tabular}

a Accession number of protein sequences in NCBI.

b No related sequences reported in $K$. marxianus. 
might be involved in the regulation of viabilities in the process of ethanol production by K. marxianus Y179.

\section{Conclusions}

A global transcriptome analysis of the non-conventional yeast, $K$. marxianus Y179, was conducted for ethanol production under various fermentative conditions. Hundreds of differentially expressed genes associated with the whole ethanol metabolism network were identified. Despite being reported as the "crabtree-negative" species, K. marxianus Y179 could achieve favorable fermentative profiles with an appropriate aeration volume, which had been verified by its transcriptional response. Genes related to oxidative stress and autophagy were apparently up-regulated or down-regulated to guarantee high cell viabilities, which were supposed to be the primary reasons of the ideal result. Moreover, the release of glucose repression and increased inulinase activity at the initial stage of fermentation, by controlling the transcription factor Mig1, may help to improve productivity. Consequently, information on the genome annotation and transcriptome data provided a valuable reference for future studies on the optimization and reconstruction of the metabolism network in $K$. marxianus.

\section{Methods}

\section{Strains, media, and culture conditions}

Kluyveromyces marxianus Y179 was deposited at the China Center for Type Culture Collection (CCTCC) with a reference number of M202031. The strain was maintained on a YPD agar slant composed of $20 \mathrm{~g} / \mathrm{L}$ glucose, $20 \mathrm{~g} / \mathrm{L}$ peptone, and $10 \mathrm{~g} / \mathrm{L}$ yeast extract at $4^{\circ} \mathrm{C}$ for routine use. For long-term preservation, cultures were stored at $-80^{\circ} \mathrm{C}$ in $20 \%$ glycerol.

\section{Genome annotation}

The genome information of $K$. marxianus was downloaded from the NCBI database (http://www.ncbi.nlm. nih.gov/Taxonomy/Browser/wwwtax.cgi?id=1162310) [8]. The whole-genome sequences above were annotated according to the Gene Ontology (GO) database and Kyoto Encyclopedia of Genes and Genomes (KEGG) database to obtain the reference genome and annotated gene information.

\section{Transcriptome analysis of $K$. marxianus Y179 Cell growth conditions}

Yeast cells that were cultivated in $100 \mathrm{~mL}$ of YPD medium in $250-\mathrm{mL}$ flasks for $16-18 \mathrm{~h}$ were inoculated into a 3-L fermenter, with a $1.0-\mathrm{L}$ working volume, at $30^{\circ} \mathrm{C}$ and $150 \mathrm{rpm}$. To study the transcriptional differences at high concentrations of substrate and aeration, three fermentation conditions were carried out: $230 \mathrm{~g} / \mathrm{L}$ inulin in YP medium $(20 \mathrm{~g} / \mathrm{L}$ peptone, $10 \mathrm{~g} / \mathrm{L}$ yeast extract) without aeration (230-N-72), $230 \mathrm{~g} / \mathrm{L}$ inulin in YP medium controlling the redox potential at $-130 \mathrm{mV}$ (230-130mV-36), and $120 \mathrm{~g} / \mathrm{L}$ inulin in YP medium without aeration (120-N-24). The ORP throughout the process was controlled by a sterile ORP electrode and a PID (Proportional, Integral, and Derivative) control algorithm, as described previously [26].

\section{RNA isolation}

Samples were taken after fermentation, under three conditions, at 72,36 , and $24 \mathrm{~h}$, respectively. Cell pellets were collected by centrifugation at $5,000 \mathrm{~g}$ at $4^{\circ} \mathrm{C}$ for $5 \mathrm{~min}$, and were then frozen by liquid nitrogen. The total RNA of every sample was extracted by the RNeasy ${ }^{\circledR}$ Mini Kit (Qiagen, Hilden, Germany) according to the manufacturer's instructions. The 2130 Bioanalyzer (Agilent Technologies, Santa Clara, CA, USA) was used to determine the RNA quality and integrity, and the RNA integrity number (RIN) of each sample used for RNA-seq was no less than 6.5.

\section{Preparation of CDNA library and sequencing}

The cDNA libraries were constructed and sequenced at the Beijing Genomics Institute (BGI, Shenzhen, China). The final cDNA libraries were qualified and quantified using the 2130 Bioanaylzer (Agilent Technologies) and the StepOnePlus Real-Time PCR System (Applied Biosystems). Afterward, the library products were ready for sequencing via the HiSeq 2000 system (Illumina). To detect the differences of gene expressions among various samples, single-end technology was used to obtain about $40-50$ bp reads in a single run.

\section{Quantification analysis of gene expression by RNA-seq}

To annotate and quantify the genes expressed in $K$. marxianus Y179, we first calculated the percentage of the gene covered by reads (gene coverage), which was determined as the ratio of the base number in a gene covered by unique mapping reads to the total base numbers of that gene. The levels of the differentially expressed genes (DEGs) were normalized by RPKM, defined as the number of reads per kilobase of the exon region per million mapped reads. Furthermore, in this article, the $\log 2$ ratio of RPKM between different samples was used to calculate the fold-change values. To screen the DEGs among various samples, we used a false discovery rate (FDR) of $\leq 0.001$ and the absolute value of the $\log 2$ ratio $\geq 1$ as the threshold to judge the significance of differential gene expression. More stringent criteria with a smaller FDR and a larger fold-change value can be used to identify DEGs. 


\section{Analysis of the DEGs of K. marxianus Y179 grown in different culture conditions}

Expression pattern analysis of DEGs was clustered using Cluster software [57] and Java Treeview software [58]. The hierarchical clustering of the chosen experimental conditions and genes was carried out using the Euclidean distance as the formula of the distance matrix.

Gene Ontology (GO) enrichment analysis and functional classification helped to simplify huge amounts of data from RNA-seq and to identify the most significant DEGs from thousands of genes. To understand the distribution of gene functions of the species on the macro level, GO functional classification for DEGs was applied using the WEGO software [59] after obtaining the GO annotation of DEGs, as described above.

Kyoto Encyclopedia of Genes and Genomes was used as the major public pathway-related database to conduct the pathway enrichment analysis to further understand the biological functions of the genes. KEGG enrichment analysis identifies the significantly enriched metabolic pathways or the signal transduction pathways in DEGs, compared with the whole-genome background, of which the $Q$ value was defined as no greater than 0.05 .

A brief introduction and procedure of the transcriptome analysis of $K$. marxianus Y179 is illustrated in Additional file 1: Figure S1.

\section{RT-PCR and real-time quantitative PCR}

RT-PCR and real-time quantitative PCR (qPCR) were performed to verify the accuracy of the gene expression levels obtained by RNA-seq. The same total RNA samples for RNA-seq were utilized to conduct the PCR reactions. The total RNA of each sample $(1 \mu \mathrm{g})$ was reverse transcribed to cDNA using the PrimeScript ${ }^{\circledR}$ RT reagent Kit (Takara Bio Inc.) according to the manufacturer's protocol. Afterward, six differentially expressed genes involved in EMP, TCA, glycerol and ethanol formation, and stress response pathways were selected to perform qPCR, and the information of the primers is shown in Additional file 1: Table S3. A 10 times dilution of CDNA solution was used as the DNA template for the qPCR reaction and $\mathrm{ddH}_{2} \mathrm{O}$ was used as the negative control. A two-step PCR reaction was employed, and the system and conditions were as described in the manufacturer's protocol of SYBR ${ }^{\circledR}$ Premix Ex Taq ${ }^{\mathrm{TM}}$ II (Takara Bio Inc.). Finally, the actin gene was selected as the endogenous reference gene, and the data analysis of the fold change of a specific gene was determined by the method of $2^{-\Delta \Delta C_{\mathrm{T}}}$ as described by Livak and Schmittgen [60]. Triplicate experiments were performed to guarantee the reproducibility of all the results.

\section{Analytical methods}

Biomass, sugar, and ethanol determination

The cell concentration was measured using the optical density at $620 \mathrm{~nm}$. Concentrations of the reducing sugar in inulin were determined by the dinitrosalicylic acid method [61], and the total sugar was firstly hydrolyzed by $0.2 \mathrm{M} \mathrm{H}_{2} \mathrm{SO}_{4}$ at $100^{\circ} \mathrm{C}$ for $1 \mathrm{~h}$, then measured by the methods of Miller [61] after adding an equivalent amount of $0.4 \mathrm{M} \mathrm{NaOH}$.

The ethanol was analyzed by gas chromatography (Agilent 6890A, Agilent Technologies) as previously described [19]. Briefly, a hydrogen flame ionization detector and isothermal capillary column (solid phase: cross-linked polyethylene glycol, carrier gas: nitrogen, and injector temperature: $250^{\circ} \mathrm{C}$ ) were operated at 250 and $120^{\circ} \mathrm{C}$, respectively.

\section{Measurement of inulinase activity}

Inulinase activity was measured according to the previous method $[19,20]$. Briefly, $0.5 \mathrm{~mL}$ of culture supernatant was incubated with $2 \%(\mathrm{w} / \mathrm{v})$ inulin prepared in $0.02 \mathrm{M}$ sodium acetate buffer $(\mathrm{pH} 4.6)$ at $55^{\circ} \mathrm{C}$ for $10 \mathrm{~min}$, and the reducing sugar was analyzed by the dinitrosalicylic acid method [61]. One enzyme unit was defined as the amount of fructose $(\mu \mathrm{M})$ hydrolyzed per minute under the above conditions. Fructose was used as the standard substance to plot a standard curve.

\section{Cell viability detection}

The viabilities of the $K$. marxianus Y179 cells were roughly detected by the methylene blue stain technique [62].

Analysis of the biomass, sugars, ethanol, inulinase activity, and cell viabilities were done in duplication, and the mean values are shown in the results section.

\section{Additional file}

Additional file 1: Figure S1. Overview of transcriptomics analysis roadmap and procedure of RNA-seq analysis. Table S1. Summary of mapping results (mapping to genome and genes) from RNA-Seq. Table S2. Summary of DEGs involved in KEGG pathways. Table S3. Primes used in qPCR analysis.

\begin{abstract}
Abbreviations
CBP: consolidated bioprocessing; ORP: redox potential; DEG: differentially expressed gene; RNA-seq: next-generation sequencing technology; qPCR: real-time quantitative polymerase chain reaction; EMP: glycolysis; TCA: tricarboxylic acid cycle; PPP: pentose phosphate pathway; GO: Gene Ontology; KEGG: Kyoto Encyclopedia of Genes and Genomes; ROS: reactive oxygen species.
\end{abstract}

\section{Authors' contributions}

JQG participated in the experimental design, data collection and mathematical modeling, and manuscript preparation. WJY conceived the concept and design of the experiment. YML, SBH, and RJX carried out microbiological sampling and conducted analyses. SJZ and FWB participated in the design of the 
study and assisted in drafting the manuscript. All authors read and approved the final manuscript.

\section{Author details}

${ }^{1}$ School of Life Science and Biotechnology, Dalian University of Technology, Dalian 116024, China. ${ }^{2}$ School of Life Science and Biotechnology, Shanghai Jiaotong University, Shanghai 200240, China.

\section{Acknowledgements}

The authors acknowledge financial support from the Natural Science Foundation of China (21106016), the National High-Tech R\&D Program (2012AA021205), and the Fundamental Research Funds for the central Universities (DUT14LK33)

\section{Compliance with ethical guidelines}

\section{Competing interests}

The authors declare that they have no competing interests.

Received: 6 May 2015 Accepted: 24 July 2015

Published online: 14 August 2015

\section{References}

1. Gunnarsson IB, Svensson SE, Johansson E, Karakashev D, Angelidaki I (2014) Potential of Jerusalem artichoke (Helianthus tuberosus L.) as a biorefinery crop. Ind Crops Prod 56:231-240

2. Kim S, Kim CH (2014) Evaluation of whole Jerusalem artichoke (Helianthus tuberosus L.) for consolidated bioprocessing ethanol production. Renew Energy 65:83-91

3. Silva TP, Paixão SM, Roseiro JC, Alves L (2015) Jerusalem artichoke as low-cost fructose-rich feedstock for fossil fuels desulphurization by a fructophilic bacterium. J Appl Microbiol 118:609-618

4. Kays S, Nottingham S (2007) Biology and chemistry of Jerusalem artichoke. CRC Press, London, pp 1-20

5. Suleau A, Jacques N, Reitz-Ausseur J, Casaregola S (2005) Intraspecific gene expression variability in the yeast Kluyveromyces lactis revealed by micro-array analysis. FEMS Yeast Res 5:595-604

6. Yuan WJ, Zhao XQ, Ge XM, Bai FW (2008) Ethanol fermentation with Kluyveromyces marxianus from Jerusalem artichoke grown in salina and irrigated with a mixture of seawater and freshwater. J Appl Microbiol 105:2076-2083

7. Yuan WJ, Chang BL, Ren JG, Liu JP, Bai FW, Li YY (2012) Consolidated bioprocessing strategy for ethanol production from tubers by Kluyveromyces marxianus under high gravity conditions. J Appl Microbiol 112:38-44

8. Jeong H, Lee DH, Kim SH, Kim HJ, Lee K, Song JY et al (2012) Genome sequence of the thermotolerant yeast Kluyveromyces marxianus var. marxianus KCTC 17555. Eukaryot Cell 11:1584-1585

9. Lertwattanasakul N, Kosaka T, Hosoyama A, Suzuki Y, Rodrussamee N, Matsutani M et al (2015) Genetic basis of the highly efficient yeast Kluyveromyces marxianus: complete genome sequence and transcriptome analyses. Biotechnol Biofuels 8:1-14

10. Ask M, Bettiga M, Duraiswamy VR, Olsson L (2013) Pulsed addition of HMF and furfural to batch-grown xylose-utilizing Saccharomyces cerevisiae results in different physiological responses in glucose and xylose consumption phase. Biotechnol Biofuels 6:181-195

11. Oda Y, Nakamura K, Shinomiya N, Ohba K (2010) Ethanol fermentation of sugar beet thick juice diluted with crude cheese whey by the flex yeast Kluyveromyces marxianus KD-15. Biomass Bioenerg 34:1263-1266

12. Silveira WB, Passos FJV, Mantovani HC, Passos FML (2005) Ethanol production from cheese whey permeate by Kluyveromyces marxianus UFV-3: a flux analysis of oxido-reductive metabolism as a function of lactose concentration and oxygen levels. Enzyme Microb Technol 36:930-936

13. Aziz S, Shah FA, Soomro SA, Memon HR, Rajoka MI (2009) Production of ethanol by indigenous wild and mutant strain of thermo tolerant Kluyveromyces marxianus under optimized fermentation conditions. Pak J Anal Environ Chem 10:25-33
14. Limtong S, Sringiew C, Yongmanitchai W (2007) Production of fuel ethanol at high temperature from sugar cane juice by a newly isolated Kluyveromyces marxianus. Bioresour Technol 2007(98):3367-3374

15. Rocha MVP, Rodrigues THS, Melo VM, Gonçalves LR, de Macedo GR (2011) Cashew apple bagasse as a source of sugars for ethanol production by Kluyveromyces marxianus CE025. J Ind Microbiol Biotechnol 38:1099-1107

16. Lane MM, Burke N, Karreman R, Wolfe KH, O'Byrne CP, Morrissey JP (2011) Physiological and metabolic diversity in the yeast Kluyveromyces marxianus. Antonie Van Leeuwenhoek 100:507-519

17. Rocha SN, Abrahão-Neto J, Gombert AK (2011) Physiological diversity within the Kluyveromyces marxianus species. Antonie Van Leeuwenhoek 100:619-630

18. Fonseca GG, de Carvalho NMB, Gombert AK (2013) Growth of the yeast Kluyveromyces marxianus CBS 6556 on different sugar combinations as sole carbon and energy source. Appl Microbiol Biotechnol 97:5055-5067

19. Gao JQ, Yuan WJ, Kong L, Xiang RJ, Zhong SJ (2015) Efficient ethanol production from inulin by two-stage aerate strategy. Biomass Bioenerg 80:10-16

20. Gao JQ, Chen LJ, Yuan WJ (2012) Effects of carbon sources, oxygenation and ethanol on the production of inulinase by Kluyveromyces marxianus YX01. J Biosci Biotech 1:155-161

21. Kawasaki G, Fraenkel DG (1982) Cloning of yeast glycolysis genes by complementation. Biochem Biophys Res Commun 108:1107-1112

22. Heinisch JJ, Müller S, Schlüter E, Jacoby J, Rodicio R (1998) Investigation of two yeast genes encoding putative isoenzymes of phosphoglycerate mutase. Yeast 14:203-213

23. Papini M, Nookaew I, Scalcinati G, Siewers V, Nielsen J (2010) Phosphoglycerate mutase knock-out mutant Saccharomyces cerevisiae: physiological investigation and transcriptome analysis. Biotechnol J 5:1016-1027

24. Benjaphokee S, Koedrith P, Auesukaree C, Asvarak T, Sugiyama M, Kaneko $Y$ et al (2012) CDC19 encoding pyruvate kinase is important for hightemperature tolerance in Saccharomyces cerevisiae. New Biotechnol 29:166-176

25. Boles E, Schulte F, Miosga T, Freidel K, Schlüter E, Zimmermann FK et al (1997) Characterization of a glucose-repressed pyruvate kinase (Pyk2p) in Saccharomyces cerevisiae that is catalytically insensitive to fructose-1, 6-bisphosphate. J Bacteriol 179:2987-2993

26. Liu CG, Lin YH, Bai FW (2013) Global gene expression analysis of Saccharomyces cerevisiae grown under redox potential-controlled very-highgravity conditions. Biotechnol J 8:1332-1340

27. Suga H, Matsuda F, Hasunuma T, Ishii J, Kondo A (2013) Implementation of a transhydrogenase-like shunt to counter redox imbalance during xylose fermentation in Saccharomyces cerevisiae. Appl Microbiol Biotechnol 97:1669-1678

28. Lushchak V, Semchyshyn H, Mandryk S, Lushchak O (2005) Possible role of superoxide dismutases in the yeast Saccharomyces cerevisiae under respiratory conditions. Arch Biochem Biophys 441:35-40

29. De Smidt O, du Preez JC, Albertyn J (2008) The alcohol dehydrogenases of Saccharomyces cerevisiae: a comprehensive review. FEMS Yeast Res 8:967-978

30. Gibson BR, Boulton CA, Box WG, Graham NS, Lawrence SJ, Linforth RS et al (2008) Carbohydrate utilization and the lager yeast transcriptome during brewery fermentation. Yeast 25:549-562

31. Lertwattanasakul N, Shigemoto E, Rodrussamee N, Limtong S, Thanonkeo P, Yamada M (2009) The crucial role of alcohol dehydrogenase Adh3 in Kluyveromyces marxianus mitochondrial metabolism. Biosci Biotechnol Biochem 73:2720-2726

32. Albertyn J, Hohmann S, Thevelein JM, Prior BA (1994) GPD1, which encodes glycerol 3-phosphate dehydrogenase, is essential for growth under osmotic stress in Saccharomyces cerevisiae, and its expression is regulated by the high osmolarity glycerol response pathway. Mol Cell Biol 14:4135-4144

33. Eriksson P, Andre L, Ansell R, Blomberg A, Adler L (1995) Cloning and characterization of GPD2, a 2nd gene encoding Sn glycerol 3-phosphate dehydrogenase $\left(\mathrm{NAD}^{+}\right)$in Saccharomyces cerevisiae, and its comparison with GPD1. Mol Microbiol 17:95-107

34. Gori K, Mortensen HD, Arneborg N, Jespersen L (2005) Expression of the GPD1 and GPD2 orthologues and glycerol retention during growth of Debaryomyces hansenii at high $\mathrm{NaCl}$ concentrations. Yeast 22:1213-1222 
35. Blanco M, Núñez L, Tarrío N, Canto E, Becerra M, González-Siso Ml et al (2007) An approach to the hypoxic and oxidative stress responses in Kluyveromyces lactis by analysis of mRNA levels. FEMS Yeast Res 7:702-714

36. Arellano-Plaza M, Gschaedler-Mathis A, Noriega-Cisneros R, ClementeGuerrero M, Manzo-Ávalos S, González-Hernández JC et al (2013) Respiratory capacity of the Kluyveromyces marxianus yeast isolated from the mezcal process during oxidative stress. World J Microbiol Biotechnol 29:1279-1287

37. Wong CM, Siu KL, Jin DY (2004) Peroxiredoxin-null yeast cells are hypersensitive to oxidative stress and are genomically unstable. J Biol Chem 279:23207-23213

38. Tachibana T, Okazaki S, Murayama A, Naganuma A, Nomoto A, Kuge S (2009) A major peroxiredoxin-induced activation of Yap1 transcription factor is mediated by reduction-sensitive disulfide bonds and reveals a low level of transcriptional activation. J Biol Chem 284:4464-4472

39. Geddes RD, Wang X, Yomano LP, Miller EN, Zheng H, Shanmugam KT et al (2014) Polyamine transporters and polyamines increase furfural tolerance during xylose fermentation with ethanologenic Escherichia coli Strain LY180. Appl Environ Microbiol 80:5955-5964

40. Aranda A, del Olmo ML (2004) Exposure of Saccharomyces cerevisiae to acetaldehyde induces sulfur amino acid metabolism and polyamine transporter genes, which depend on Met $4 p$ and Haa1p transcription factors, respectively. Appl Environ Microbiol 70:1913-1922

41. Kim SK, Jin YS, Choi IG, Park YC, Seo JH (2015) Enhanced tolerance of Saccharomyces cerevisiae to multiple lignocellulose-derived inhibitors through modulation of spermidine contents. Metab Eng 29:46-55

42. Horák J (2013) Regulations of sugar transporters: insights from yeast. Curr Genet 59:1-31

43. Goffrini P, Wesolowski-Louvel M, Ferrero I, Fukuhara H (1990) RAG1 gene of the yeast Kluyveromyces lactis codes for a sugar transporter. Nucleic Acids Res 18:5294

44. Billard P, Ménart S, Blaisonneau J, Bolotin-Fukuhara M, Fukuhara H, Wésolowski-Louvel M (1996) Glucose uptake in Kluyveromyces lactis: role of the HGT1 gene in glucose transport. J Bacteriol 178:5860-5866

45. Diezemann A, Bole E (2003) Functional characterization of the Frt1 sugar transporter and of fructose uptake in Kluyveromyces lactis. Curr Genet 43:281-288

46. Nehlin JO, Ronne H (1990) Yeast MIG1 repressor is related to the mammalian early growth response and Wilms' tumour finger proteins. EMBO J 9:2891-2898

47. Cassart JP, Ostling J, Ronne H, Vandenhaute J (1997) Comparative analysis in three fungi reveals structurally and functionally conserved regions in the Mig1 repressor. Mol Gen Genet 255:9-18
48. Draper MP, Salvadore C, Denis CL (1995) Identification of a mouse protein whose homolog in Saccharomyces cerevisiae is a component of the CCR4 transcriptional regulatory complex. Mol Cell Biol 15:3487-3495

49. Hata H, Mitsui H, Liu H, Bai Y, Denis CL, Shimizu Y et al (1998) Dhh1p, a putative RNA helicase, associates with the general transcription factors Pop2p and Ccr4p from Saccharomyces cerevisiae. Genetics 148:571-579

50. Amorós M, Estruch F (2001) Hsf1p and Msn2/4p cooperate in the expression of Saccharomyces cerevisiae genes HSP26 and HSP104 in a gene- and stress type-dependent manner. Mol Microbiol 39:1523-1532

51. Skoneczna A, Miciałkiewicz A, Skoneczny M (2007) Saccharomyces cerevisiae Hsp31p, a stress response protein conferring protection against reactive oxygen species. Free Radic Biol Med 42:1409-1420

52. Schiavi A, Ventura N (2014) The interplay between mitochondria and autophagy and its role in the aging process. Exp Gerontol 56:147-153

53. Cebollero E, Reggiori F (2009) Regulation of autophagy in yeast Saccharomyces cerevisiae. Biochim Biophys Acta 1793:1413-1421

54. Kissová I, Salin B, Schaeffer J, Bhatia S, Manon S, Camougrand N (2007) Selective and non-selective autophagic degradation of mitochondria in yeast. Autophagy 3:329-336

55. Xie Z, Nair U, Klionsky DJ (2008) Atg8 controls phagophore expansion during autophagosome formation. Mol Biol Cell 19:3290-3298

56. Xie Z, Nair U, Geng J, Szefler MB, Rothman ED, Klionsky DJ (2009) Indirect estimation of the area density of Atg8 on the phagophore. Autophagy 5:217-220

57. de Hoon MJL, Imoto S, Nolan J, Miyano S (2004) Open source clustering software. Bioinformatics 20:1453-1454

58. Saldanha J (2004) Java Treeview-extensible visualization of microarray data. Bioinformatics 20:3246-3248

59. Ye J, Fang L, Zheng H, Zhang Y, Chen J, Zhang Z et al (2006) WEGO: a web tool for plotting GO annotations. Nucleic Acids Res 34:293-297

60. Livak KJ, Schmittgen TD (2001) Analysis of relative gene expression data using real-time quantitative PCR and themethod. Methods 25:402-408

61. Miller GL (1959) Use of dinitrosalicylic acid reagent for determination of reducing sugar. Anal Chem 1959(31):426-428

62. Bai FW, Chen LJ, Zhang Z, Anderson WA, Moo-Young M (2004) Continuous ethanol production and evaluation of yeast cell lysis and viability loss under very high gravity medium conditions. J Biotechnol 110:287-293

\section{Submit your next manuscript to BioMed Central and take full advantage of:}

- Convenient online submission

- Thorough peer review

- No space constraints or color figure charges

- Immediate publication on acceptance

- Inclusion in PubMed, CAS, Scopus and Google Scholar

- Research which is freely available for redistribution

Submit your manuscript at

www.biomedcentral.com/submit

C BioMed Central 